\title{
XLII. An essay on dreaming, including conjectures on the proximate cause of sleep
}

\author{
Andrew Carmichael M.R.I.A.
}

To cite this article: Andrew Carmichael M.R.I.A. (1819) XLII. An essay on dreaming, including conjectures on the proximate cause of sleep, Philosophical Magazine Series 1, 54:258, 252-264, DOI: $10.1080 / 14786441908652223$

To link to this article: http://dx.doi.org/10.1080/14786441908652223

曲 Published online: 29 Jul 2009.

Submit your article to this journal $[\pi$

Џ Article views: 2

Q View related articles $\asymp$ 
If any of your correspondents could furnish you with these documents, I feel assured that you would most readily make room for their insertion in the pages of your Magazine.

XLII. An Essoy on Dreaming, including Conjectures on the proximate Cause of Sleep. By ANDrew Carmichazl, M.R.I.A.*

Dreams have perplexed every individual who has attempted to account for them; but it will scarcely be credited that a philosopher of the eighteenth century, who was acquainted with the opinions of Locke and had controverted with ability the theory of Berkeley, should find no other mode of explaining these phrnomena, than by maintaining that "our dreams are prompted by separate immaterial beings $+; "$ and in illustration of the nature of uneasy dreams during illness, could argue that " these beings wait for and catch the opportunity of the indisposition of the body, to represent at the same time something terrifying also to the mind $f . "$

But to arrive at a more rational explication, we must revert to this author's predecessors. "Dreaning (says Locke) is the having of ideas (whilst the outward senses are stopped, so that they receive not outward objects with their usual quickness) in the mind, not suggested by any external objects or known occasion, nor under any choice or conduct of the understanding at all §;", and again, " this I wonld willingly be satisfied in, whether the soul when it thinks thus apart, and as it were separate from the body, acts less rationally than when conjointly with it, or no? If its separate thoughts be less rational, then these men inust say that the soul owes the perfection of rational thinking to the body: if it does not, it is a wonder that our dreans should be for the most part so frivolous and irrational, and that the soul should retain none of its more rational soliloquies and meditations $\| . "$ We mig!ht almost imagine that this passage was composed in support of the Organic Theory since developed by Gall. Some feeble anticipation of such a system seems to have been floating in the mind of Locke.

* From the Transactions of the King's and Queen s College of Physicians in Ireland.

+ An Inquiry into the Nature of the human Soul, wherein the Immateriality of the Soul is evinced from the Principles of Reason and Philosophy. Anon.-no daie-p. 215.

I I. 257 . I have lately found that this is the first edition of Baxter's celebrated Lssav.

§Locke's Essay, 2Ist edition, vol. I, p.213. UId. p. \$7.

Hartley 
Hartley seems also but little inclined to attribute these phænomena alone to the soul. His views, as far as they go, are clear and satisfactory. "Dreams (he says) are nothing more but the imaginations, fancies or reveries of a sleeping man; and they are deducible from the three following causes : 1 st, The impressions and ideas lately received, and particularly those of the preceding day. $2 \mathrm{~d}$, The state of the body, particularly the stomach and brain. 3d, Association*." "The scenes which present themselves are taken to be real, we do not consider them as the work of the fancy; but suppose ourselves present and actually seeing and hearing what passes. Now this happens, because we have no other reality to oppose to the ideas which offer themselves: whereas, in the common fictions of the fancy, while we are awake, there is always a set of ' real external objects striking some of our senses, and precluding a like mistake there : or, if we come quite inattentive to external objects, the reverie does so far put on the nature of a dream as to appear a reality $\dagger$."

Beattie appears to have entertained a very confused idea of the nature of the soul, and even to have conceived that some of her faculties fall asleep while others remain awake. He does not, however, exclude the influence altogether of the corporeal organs. "The imagination or fancy (he remarks) seems to be almost the only one of our mental powers which is never suspended in its operations by sleep; of the other faculties, some are more and others less affected, and some appear to be for a time wholly extinguished $¥ . "$ "Persons (he continues) who think much and take little bodily exercise, will, perhaps, be found to be the greatest dreamers ; especially, if their imagination be active, and their nervous system very delicate $\S . "$

Darwin's doctrine is also connected with corporeal relations, as may be found in his observation, that the "perpetual flow of the trains of ideas which constitute our dreams, and which are eaused by painful or pleasurable sensation, might at first view be conceived to be an useless expenditure of sensorial power $\| . "$ We at least learn that, in his opinion, they really occur during an accumulation of this power, when he adds, that " our dreams in the morning have greater variety and vivacity, as our sensibility inereases, than at night when we first lie down I." But this hypothesis is not less vague, though apparently more philosophic, than the exploded systems of the nervous fluid and animal spirits. The sensorial power is in fact the nervous fluid stripped of its substance and reality, and reduced to a quality or attribute.

* Hartley on Man, quarto, p. 226.

+ Id. p. 227.

$\ddagger$ Beattie's Dissertations, moral and critical, vol. 1, p. 272 .

$\S$ Id. p. 274 .

ป Id. p. 302 .

t| Zoonomia, London 1801, vol. 1, p. 287.

Professor 
Professor Stewart's explanation is altogether psychological, but, however ingenious, is not even satisfactory to himself. He maintains " that all our mental operations which are independent of our will, may continue during sleep; and that the phænomena of dreaming may perhaps be produced by these, diversified in their apparent effects in consequence of the suspension of our voluntary powers *." "That the same laws of association, which regulate the train of our thoughts while we are awake, continue to operate during sleep; but the influence of the will being suspended, all our voluntary operations, such as recollection, reasoning, \&c. must also be suspended + ."

To this hypothesis he tells us that Mr. Thomas Browne and Mr. Prevost offered one and the same objection, viz. That unless the will were active, there could be no effort of attention, and without such an effort, there could be no recollection: yet we recollect our dreams, although the hypothesis supposes that in sleep the will does not operate. Professor Stewart expresses himself sensible of the force of this objection, and acknowledges that he is far from being satisfied that it is in his power to reconcile completely the apparent inconsistency. He, however, adopts a solution offered by Mr. Prevost, viz. that in perfect sleep there is no recollection; and that when we remember our dreams, our sleep has not been perfect. And he adds, that in bodily indisposition, the disturbed state of our rest may prevent the total cessation of the power of attention, which may enable us afterwards to retrace our dreams, or some acciciental assuciation may renew the train of ideas; and if we are -satisfied that they once passed through our mind, yet not during our waking moments, we have no other alternative but to regard them as a dream $\ddagger$.

This last observation can scarcely be controverted. On awaking in the morning, we naturally advert to the occupations which are to employ us during the day, and the persons with whom we wish or expect to communicate. The moment they occur in our reflections, we perhaps recollect that we have been dreaming of them. But surely this is only an argument that our sleeping thoughts are recalled, like our waking, by the association of our ideas. It neither proves nor disproves his hypothesis. If the influence of the will, and the exercise of attention, may be suspended during the course of those thoughts which pass through our mind while asleep, and which yet may be recalled by the force of association, so may they be suspended also during our waking thoughts, and with a similar result. But, if they be necessary to our recollection in one case, they must in the other.

* Philosophy of the human Mind, octavo, p. 333 .

† Id. ib.

¥ Id. note 0 . 
With respect to the former solution of the difficulty, viz. that the disturbed state of our rest may prevent the total cessation of the power of attention, or, in other words, that we are not quite asleep during dreams, (which by the way appears the most prevalent opinion entertained at present on the subject, it is only necessary to consider the difference between sleeping and waking, and reflect on our daily experience, to subvert the position. So long as we sleep, we are, with some singular exceptions, either totally insensible, or sensible only of internal sensations. In the transition from sleeping to waking, we are perhaps passively and involuntarily sensible of external impressions. . And when these force themselves on our attention, or when we can voluntarily attend to them, from that moment we are fully awake. Nor are we conscious of being awake until we perceive thase impressions, whether by compulsion, or with our will. Sometimes we notice the very moment this occurrence takes place; but in general, if we are not suddenly awakened, we perceive our sleep gradually retiring-we are reluctant to resign its embraces; we cling to it as long as we can; thoughts pass in crowded trains through our minds; yet these thoughts are not dreams. They assume no bodily shape or visionary semblance-we regard them as we do the current of our waking reflections, we direct their course as we please, and we know that we can break through the dubious remnant of our sleep, the moment that we will. It is otherwise when we actually sleep. The generality of our thoughts assume a corporeal appearance, and pass in fantastic procession before us. If our dream be terrific, we struggle to escape from the object of horror, and that struggle awakes us. Once to a certain extent awake, we banish with an effort the little residue of sleep; that effort is an act of the will; but whether our previous visionary struggle can also be ascribed to its power, is a question too involved for me to disentangle.

Yet I am tempted to venture a reflection which, upon the principles of the new philosophy, may lead to a solution of the difficulty. If a single organ be awake, and a single motive be presented to it, it acts in obedience to that motive without choice, without judgement, without a decision, and, of course, without any intervention of the will. But if two motives offer themselves to the faculty in question, and it chooses between them, or if two organs are awake, and judge between the claims of two opposite motives, one applicable to this, and the other to that propensity or sentiment, and that a decision is the result, whether to act or to forbear, to pursue or to fly, this decision, though in a dream, appears to be an act of the will. It would be called so without hesitation, if these operations happened to take place 
during our waking moments. Are we then to conclude, in opposition to so respectable an opinion as that of Professor Stewart, that our voluntary powers are not always suspended when we dream?

But these are not the difficulties which appear to me to weigh most against his hypothesis.

In supposing that the influence of the will is suspended, it also supposes, as this revered philosopher expresses himself, that all our voluntary operations, such as recollection, reasoning, \&c. must also be suspended.-If there be in nature pure mental operations, recollection and reasoning are entitled to the rank; yet we learn from this hypothesis that a simple essence, such as the soul is considered, can be at the same moment, with respect to its different powers, awake and asleep-all its operations which are independent of the will may continue, but its recollection and reasoning must be absolutely suspended. Dr. Beattie's explanation involves the same incongruity. All the faculties, according to him, are more or less affected, and-some for a time wholly extinguished, while the operations of imagination or fancy are alone unsuspended by sleep. The elucidations of Hartley are exempt from this inconsistency, and remove every difficulty but onewhy sometimes we dream, and sometimes do not. Darwin repeats an exploded hypothesis in a more plausible form. Locke simply discusses the phænomena of dreaming in proof of his position, that men think not always; he does not attempt to account for them; yet from the questions detailed in the passage I have quoted above, it is manifest that he was inclined to refer the explanation to organic rather than to spiritual operation.

If we but do so likewise, all these difficulties vanish; we are not driven to the absurdity of supposing that sleep is necessary to a pure spirit, and that its simple essence may be half asleep and half awake - a moiety of its powers suspended or extinguished, and another moiety active and busy. We may look for the solution in the corporeal organs of the soul, and not in the soul itself; there is nothing incongruous in supposing that some of these organs may be in a state of activity while others are at rest. "Watching (says Dr. Spurzheim) is called the state wherein the will can put in action the organs of the intellectual faculties, of the five senses, and of voluntary motion; but it is impossible to define watching as the state wherein all these organs are active, for it cannot happen that all the faculties should be active at the same time; all organs, being fatigued, take rest, and this state of rest is sleep; but any particular organ, or even several organs, may be active while the other organs rest; then the peculiar sensations or ideas which result from this particular activity constitute 
constitute that which is called dreams, whieh are more or less complicated according to the number of the active organs *."

This, on a comparison with the preceding opinions, appears to be a probable and satisfactory explanation, as far as it goes; but our curiosity requires a more detailed elucidation of the nature of sleep. It may properly be said, that it is rest after fatigue; but we know that it is something more. We can rest when it is necessary, without that intense and predominant change which locks up our senses and intellect, and envelops us with inadvertence and oblivion of the past, present, and future. We cannot reflect on the nature of this state, without being satisfied that it involves some important vital process, so indispensable as to be of daily recurrence, and of such general influence as to engage every part of the frame, but particularly the organs of thinking, sensation, and voluntary motiou. If we ask ourselves what process is of prime necessity to those organs, we can answer without difficulty, that which repairs their waste, and preserves their consistence and vigour-the process of assimilation. Whatever may be the result of its operation in the bones and muscles and other coarser parts of the body, we can scarcely reflect on its action upon the delicate texture of the brain and nerves, without perceiving that it must be accompanied by powerful and overwhelming effects. These are the fragile instruments of thought, feeling, and motion; and no wonder that a change which affects their very structure should be attended with a cessation of their functions, and the actual paralysis of sleep.

Yet this is but a conjecture; and so obscure and inaccessible is the subject, that, however we may wish for certainty, we must be contented with mere plausibility. There is no decisive fact to support the position; and, like first principles, if its own reasonableness does not carry with it conviction, it must, for the present, remain destitute of proof. Still we ought not to disregard any phænomenon that may lead to clearer views of the subject. Most animals sleep shortly after their meals; and there are few climates in which men do not allow themselves the same indulgence. In these countries, this is not so generally the practice; and it may be a question, whether it is not by an effort that we at first acquire a habit not natural to us, and overcome one which we originally found to be almost irresistible, and to which, perhaps, we should be compelled to submit, if we were not able to interrupt or suspend the process of assimilation in the nervous system. It is true that we can have no direct influence over this process in the grosser parts of the frame; but our power may be more extensive in the seat of the intellect. By an effort we can

- Spurzheim's Physiognomy, lsi edition, p. 216.

Vol, 54. No. 258. Oct. 1819. 
continue to think-by thinking we exercise the organ of thought -by exercising the organ we may possibly interrupt or defer this process, whose invasion, when effectual, subdues every faculty of the mind. Young children are destitute of this power-they sleep almost incessantly; but nutrition and assimilation are comparatively more necessary to them than to adults, and are carried on in a more than proportionate measure in their system. Old persons are drowsy, and find it difficult to keep themselves awake after food, yet court sleep in vain during the hours they have been accustomed in the earlier part of their life to expect it. This may be because their debilitated powers do not enable them to suspend the process of assimilation, and they are compelled to submit to its influence as soon as it operates; while the decay of nature, at the same time, evinces that the function in question is less constantly, regularly, or effectually performed : nor is the fact to be forgotten, that disturbed sleep and frightful dreams have frequently been ascribed to disorder of the digestive organs, whose preparatory office is indispensable to nutrition and assimilation.

It is true, that sleep after meals is most irresistible while the food is still in the stomach, after digestion has commenced, and long before assimilation has taken its turn. But we are ignorant how far the arrival of new matter in the blood-vessels may instantly contribute to the deposition of the old ; as an additional number of balls put into a tube, at one extremity, will force out some of their predecessors at the other.

I enter into no argument on the subject. I repose on the rational presumption that sleep is something more than rest after fatigue- that it is probably the consequence of an important vital process in the delicate and fragile instruments of the mindand that no process can be more requisite to those instruments, nor more likely to produce the effect, than the process of assimilation.

That this process is the proximate cause of sleep, receives the strongest confirmation from the facts detailed in the article SLEEP, in Rees's Cyclopcedia, probably the last and best treatise on the subject, and which evidently points throughout to this cause, though the able writer of the article inadvertently suffered it to escape his attention. He appears to be satisfied with the common explanation, and adopts the unsatisfactory opinion that "6 the exhaustion of the powers of the animal organs, by exercise, is the determining cause of sleep *." Yet he adverts to two facts, of a general nature and decisive imporance, which subvert this opinion. "Some," says he, "have called foetal existence a

- Rees's Cyclopadia, 23d vol. article sLeEp. 
perpetual sleep; but the animal organs, never having yet been exercised, can hardly be said to be in a state of repose*." "The state of torpidity," he continues, "in which many animals pass the winter months, cannot properly be called sleep; it is not the repose of the animal organs consequent on fatigue produced by their exercise, but is a peculiar condition of the whole frame, affecting the internal as well as the external organs, and caused directly by the action of the cold.$+ "$

These two causes are alike in one particular, the sleep is not repose after fatigue. In the former, the process of assimilation is proceeding in every part of the frame, and in the brain as well as elsewhere-its operation, therefore, cannot be excluded from such participation in the phænomenon as it may be reasonable to assign it. In the latter case it is well known that the bear, the marmot, and other hybernating animals retire to their winter's repose in a state of corpulence and obesity, which they lose before they shake off their slumber in spring. They use little or no food in their retreat, yet the absorption of their superfluous flesh and fat may be applied by the assimilating process to the nourishment of the superior organs, including the brain. If the coin alone reduced them to a state of torpidity, by paralysing this organ, their emaciation would still remain to be accounted for; but the action of the absorbents and the process of assinilation remove every difficulty and explain every fact.

In complete sleep, hunger and thirst are not felt, as remarked by the same writer, " yet great hunger prevents sleep; and cold, affecting a part of the body, bas the same effect. These causes operated on the unfortunate woman and her family, who lived thirty-four days in a small room overwhelmed by the snow, with the slightest sustenance : they hardly slept the whole time $f .3$ It does not clearly appear why the cold should have affected only a part of the body, and it is declared by this writer, "that intense cold, affecting the whole body, exhausts the animal powers

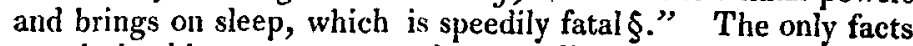
certain in this account are, that they lived for thirty-four days with the slightest sustenance, and hardly slept the whole time. The process of assimilation might therefore have been only in proportion to the nourishment, and the want of sleep seems to be accounted for by the absence of this process. If the cold had affected only a part of the body, and was not intense, it might have kept the thoughts active, and the exercise of the brain might, for a time, have interrupted the process of assimilation, even if there had been the usual supply of nutriment; but if the cold had invaded the entire frame, and was in the highest state of inten-

* Rees's Cyc.Ib.

+ Id.

$\ddagger$ Id.

§ Id.

R 2

sity, 
sity, its mode of action would probably have been, not to exhaust the animal powers, but to paralyse the brain itself. The sleep it would induce must the tefore be speedily fatal.

But in the instance of this woman and her family, it may still be said, that the absence of sleep is sufficiently accounted for by the unintermitting pain of cold and hunger. But more violent pain than that of either condd not postpone-sleep for any considerable duration. "Even stripes and tortures cannot keep off sleep heyond a certain time *."

If a great exhaustion of the animal powers-or possibly, to advance a step mearer to the actual fact-if a great exhaustion of the substance of the brain and nerves should be the consequence of torture or over-exertion, such a state of those organs must be favourable to the occurrence of the assimilating process; and if there is a supply of nourishment in the frame, it naturally takes place, and the disturbance it necessarily creates in renewing those delicate substances, may be the occasion of sleep: if there is no nourishment to renew them, the consequence is not sleep, but death: if there is nourishment, and that the torture or the labour is beyond the streng th of the individual to endure, the brain, as already mentioned in the case of excessive cold, becomes torpid and paralysed, and death, under these cireumstances, aiso follows of course.

It is well worth inquiry, whether those various vegetable substanees, which, being taken into the stomach, "bring on a condition of the brain favourable to sleep $t$," do not operate in the stme manner; and in place of producing the process of assimilation, affect the brain with a temprorary paralysis.-If they bring on this process, they must he useful auxiliaries-if not, and this is the more probable part of the dilemma, whatever be their apparent effects, they can only be prejudicial, unless where they are administered, not as soporifies but as anodynes.

The several circumstances just under review, afford an easy explication of the numerous facts detailed by the same writer. There is no reason to suppose that the process of assimilation had not materials to carry on its operations in " those boys who were completely exhausted by exertion, and fell asleep amid all the tumult of the battle of the Nile $\ddagger$," nor in the soldiers "sleeping amid discharges of artillery, and all the tumult of war," "nor the couriers sleeping on horseback, nor coachmen on their coaches." This last is a very comnon phænomenon in this country; but I fear we must ascribe the peculiarity in question rather to the paralysing effects of vegetable products taken into the stomach, than to the more wholesome accession of the assimilating process.

$$
\text { * Rees's Cyc. †Id. IId. }
$$


Most of the other circumstances mentioned by this writer have already been adverted to, and they are all of easy and obvious explanation upon the proposed hypothesis; for example, "indigestion and various bodily affections produce sleeplessness *." From preceding observations, it may readily be understood, that in $\mathrm{dl}$. gestion the uutritious matter continues in the stomach, instead of being carried into the system, and deposited in its due proportion in the brain and nerves، "All mental occupations attended with intense thought and great interest prevent sleep, and any great affections of the mind have the sane effect.$+ "$ The solution of this phænomenon has already been given; but it is here to be noticed, that the very intensity of these meditations and passions in a certain time induces sleep. They exercise and exhaust the brain, and this exhaustion renders a renewal necessary by assimilation; and according to the hypothesis, this prosess cannot act on the substance of the brain, without occasioning sleep.

"A full repast is often followed by sleep, even in animals, as dogs. The distention of the stomach excites the circulation, and this brings on a condition of the brain favourable to sleep ₹." Thiscondition, under the circumstances here noticed, can scarcely be any other than the activity of the assimilating process. "After the sleep has lasted long enough to restore the animal powers, we awake without any change or occurrence which can be shown to affect particularly the brain or other parts, of which the action was' suspended by sleep §." In other words, after the exhausted substance of the brain and nerves has been renewed by the assimilating process, we awake from the sleep which was the concomitant of its aetion. It would not be easy by any experiment to show that any change had taken place in those parts; but the fresh vigour with which we think and act is, in some degree, a proof of this change, and which is indeed implied in the very phraseology of this writer-" the restoration of the animal powers."

He adds, "There are rare examples of individuals who have gone on sleeping for days, weeks, and months; but these histories are not aceompanied with such particulars as would enable us to judge of the cause $\| . "$ It would be well worthy the attention of future inquirers to ascertain whether there are such facts in those cases, as would decide whether the cause of this state of torpor is not the protracted duration of the assimilating process: such, for instance, as the patient being overburthened with the obesity of a bear or a marmot in the commencement of his slumbers, and, like them, emaeiated at their termination, without any other assignable cause for the ehange. It is, however, a
* Rees's Cyc.
+ Id.
$\mathrm{R}^{\ddagger \text { Id. }}$
\$Id.
II Id. well- 
well-known fact, that corpulency predisposes to sleep, and sleep to corpulency. Does this happen because during sleep the process of assimilation is most active in every part of the frame? Having produced an exuberance of flesh and fat, these productions may become in their turn the cause of somnolency, by conducing to the more partial activity of the process in the brain; or at least the superfluous accumulation may form a kind of reservoir for the essential purpose of renovating the superior vital organs, when the usual measure of nutrition is no longer supplied.

Thus we may clearly comprehend the different, yet strangely analogous modes of action of vegetable poisons, intense cold, external injuries, and the assimilating process, on the brain. They all render it comatose, torpid, and paralysed; but none of them, except the last, are endowed with any but destructive powers. The assimilating process alone can renovate and restore the drained and exhausted organ : and even though the effect of its activity is to sink us in stupefaction, that very stupefaction is natural, refreshing, revivifying sleep.

A very formidable objection to this theory has, however, occurred to me. If the deposition of new matter by the bloodvessels creates such a disturbance in the brain, as to occasion the paralysis of sleep, why should not the action of the absorbents produce a similar effect, and, in removing the old matter, also bring on the same state of torpor and insensibility? That it does rot, must be distinctly admitted; for the action of those vessels cannot but exist as well in the brain as elsewhere during our waking moments, and is probably'most powerful during the intensity of thinking, as well as of bodily exercise. But if the hypothesis be true, this difficulty must admit of a solution. Can we then discover such a difference between the operation of these two actions on the brain, as will sufficiently account for circumstances so opposite?

In absorption, those particles which are removed, may leave the remaining cerebral mass in the very act of thinking, or at leasit not unfitted for the function. Every particle of the mass has already formed a part of the instrument destined to this office, and subservient to the exercise of one or other of the mental faculties. The new particles have never been exercised in any mode of thinking. They can differ but little, on their first arrival, from so many foreign bodies of equal dimensions ; and is it surprising, that the oppression occasioned by their deposition should be felt throughout the delicate volume of the brain, until they are perfectly assimilated with the other particles, and fitted like them for mental operations? - a result which may, perhaps, in some measure be effected by the very sleep which they induce. 
The nervous fiuid and animal spirits have long since been exluded from all agency in the system. It is, therefore, scarcely necessary to advert to the antiquated theory of Haller, who, in seeking for the proximate cause of sleep, conjectures that this phænomenon " arises either from a simple absence, deficiency, and immobility of the spirits, or from compression of the nerves, and always from the motion of the spirits through the brain being impeded *" "But that, if while the rest of the emporium of the senses and muscular motion is at rest, some part remains open, is pervaded by the spirits, and watches," then, that our dreams occur; and also somnambulism, "if certain voluntary motions are conjoined with the perceptions of the mind.$+ "$ Yet, it is satisfactory to perceive, that all the explanation that this great physiologist endeavoured to derive from these imaginary essences, to satisfy his rational thirst of inquiry, may be found in the substantial reality of the brain and nerves-their partial exhaustion by exercise, and their indispensable renewal by the process of assimilation.

This diurnal operation may begin later, or cease earlier, in some portions of the brain and nerves than in others. Those portions, while exempt from its influence, may be as active as the entire system would be, were the individual awake. The thoughts which originate in these vigilant organs, not being compared by means of the senses with external objects, assume the substantial forms of reality, and constitute our dreams. Volition, as far as it is inherent in any organ, may exert itself to the extent of its power. But it can have no power to stimulate the neighbouring organs which continue asleep, or to put the limbs in motion, whose nerves remain subjected to the assimilating process which renders them torpid. But if those nerves have recovered from its effects, they will naturally submit to any volition accustomed to govern them-and this circumstance will account for all the perplexing mysteries of somnambulism. This phæuomenon is of rare occurrence; and the nerves of motion are so seldom exerted in sleep, that hitherto the will has then been supposed in a state of abeyance. But we can much more rationally accounit for the various phænomena of dreams, night-mare and somnambulism, by supposing that the will may be active in any of the cerebral organs which happen to be awake, yet destitute of power to put the limbs in motion as long as the nerves of those limbs are involved in the stupor of sleep, and invested with this power from the moment that the stupor in question is removed from those nerves. But it is not to be forgottenn, that if the brain be altogether paralysed by sleep, so must the whole body. Som-

* Haller's First Lines of Physiology, p. 285. Edinburgh, I80I.

$\uparrow$ Id. p. 283. 
nambulism, therefore; can only take place when part of the brain is awake, and in communication with the nerves of locomotion. These considerations, with others detailed above, will ałso suffice to account for the fact recorded by the excellent writer so often referred to, "' that many soldiers, in the retreat of Sir John Moore, fell asleep on the march, and still continued to walk with their comrades*."

But whatever may be thought of these speculations, there is no difficulty in comprehending Dr. Spurzheim's development of the nature of dreaming: and if we are acquainted with the inadequate theories of his predecessors, to comprehend his explanation is but an easy step to its unqualified adoption. It accounts for every phænomenon connected with the subject, hitherto unexplained. If the whole brain is locked up in sleep, there is no dream. If a portion of it is emancipated, thoughts peculiar to that portion arise, and those thoughts are dreams. Tlie mechanic's imagination may rove anong machinery, the mathematician may solve a problem, the orator pour forth unstudied eloquence, the poet nupremeditated verse, the wit delectable jests, the musician unprecedented harmony; yet this does not always occur, but occasionally. If the peculiar organ happens to be asleep, there is no music, no wit, no poetry, no oratory, no mathenatics, no mechanics - a different faculty may be active, and these individuals may wander through inextrieable difficulties; or fly before wild beasts, or combat with enraged assailants, or dissolve in a cold sweat at the frightful visit of some spectre from the grave. It is not because the organ may have been frequently or recently exercised, that it is employed in a dream; it is simply because it has escaped from the trammels of sleep which still envelop the remainder of the brain, or at ledst the senses; which open a communication with the external world, and supply the only means by which we are informed whether similar objects of thought are realities or illusions: This theory, therefore, explains why we sometimes have dreams and are sometimes without them-why we sometimes dream on the subject most familiar to our reflections, and sometimes ramble in to the most unaccountable fancies - and lastly, why happiness and misery are occasionally the companions of our sleep, according as peculiar organs are gently affected or rudely agitated by the thoughts which engage them-pleasure frequently losing itself in pain; as the mental disturbance increases, till at length the accumulating uneasiness trespasses on the sensorium, or the very organs of sense, when, suddenly awaking, we find an unexpected relief from our griefs, vexations, and terrors.

[To be continued.]

* Rees's Cyc. article sLEep. 